\title{
Imatinib as the first and only treatment in Europe for adult patients at significant risk of relapse following gastrointestinal stromal tumor removal
}

This article was published in the following Dove Press journal:

Clinical and Experimental Gastroenterology

II May 2010

Number of times this article has been viewed

F Duffaud

$S$ Salas

T Huyn

JL Deville

La Timone University Hospital,

Marseille, France
Correspondence: F Duffaud

Oncology Unit, La Timone University Hospital, Bld J Moulin, I3385 Marseille cedex 5 , France

$\mathrm{Tel}+33491385708$

$\mathrm{Fax}+33491387658$

Email fduffaud@mail.ap-hm.fr

\begin{abstract}
Mutations of the KIT gene are the molecular hallmark of most gastrointestinal stromal tumors (GISTs). GIST has become a model for targeted treatment of solid tumors, imatinib becoming the standard first-line treatment of these tumors in the advanced/metastatic phase. Because of the efficacy of imatinib treatment in the advanced setting, its role following resection of a primary non-metastatic GIST was investigated. The recently published phase III, doubleblind, placebo-controlled, multicenter ACOSOG Z9001 study showed that adjuvant therapy is safe, and significantly improves recurrence-free survival compared to placebo when given after resection. To what extent imatinib will improve overall survival has yet to be answered. What is clear is that high-risk GIST patients definitely need adjuvant therapy, and that 1 year of imatinib is not enough for the patients who do need it. The questions of optimal duration of imatinib treatment in the adjuvant setting, adequate selection of risk patients and effect of imatinib on overall survival are currently being studied.
\end{abstract}

Keywords: GIST, gastrointestinal stromal tumors, imatinib, adjuvant therapy

\section{Introduction}

Gastrointestinal stromal tumor (GIST) is the most common mesenchymal tumor of the gastrointestinal (GI) tract, ${ }^{1}$ with an annual incidence of approximately 7 to 19 cases per million. ${ }^{2-4}$ They are thought to be derived from the interstitial cells of Cajal or a common precursor, based on immunohistochemical and ultrastructural data. They account for $<1 \%$ of all GI tumors. ${ }^{5}$ GISTs affect men slightly more often than women. At the time of diagnosis, the majority of patients are aged 40 to 80 years with a median of 60 years. ${ }^{3}$ They may arise anywhere along the GI tract, but they are most commonly found in the stomach $(60 \%)$ and small intestine $(25 \%) .{ }^{6}$ Less frequently, GISTs are found in the rectum, esophagus or rarely at extragastrointestinal sites such as the omentum or mesentery. As clinical presentation of GIST is variable, diagnosis can be challenging in some cases. GISTs are often asymptomatic and discovered incidentally. When symptoms do arise, they depend on the location and size of the tumor. Signs or symptoms of GIST include early satiety, bloating, vague abdominal pain or discomfort, weight loss, nausea, GI hemorrhage, a palpable abdominal mass, and additional GI complaints. GI bleeding is the most common sign of GIST, and while fatigue from anemia is a frequent symptom indicative of chronic bleeding, acute hemorrhage can also occur. ${ }^{7}$

Most GISTs are sporadic, although a few families with germline mutations have been reported with KIT mutation or platelet-derived growth factor $\alpha$ (PDGFR $\alpha)$ mutation. ${ }^{8,9}$ Activating mutations of KIT and less commonly PDGFR $\alpha$, which 
encode the stem-cell factor receptor $(K I T)$ and PDGFR $\alpha$ tyrosine kinases, respectively, are believed to be pivotal in the molecular pathogenesis. ${ }^{10}$ Such activating mutations cause constitutive activation of the tyrosine kinase activity of these receptors and consequently activation of downstream signaling pathways. GISTs exhibit activating KIT mutations in $80 \%$ to $85 \%$ of cases. The remaining tumors (10\% to $15 \%)$ either exhibit an activating mutation of the PDGFR $\alpha$ gene, or show no mutations of these two genes. This latter group is generally referred as to as "wild type" GIST. ${ }^{10}$

Once diagnosed, the curative treatment of a primary GIST is based on surgical excision of the tumor. The aim of the procedure is to achieve complete en bloc resection of the lesion, with clear R0 margins, and to avoid tumor rupture or spillage. Recurrence following surgery has been reported in $11 \%$ to $56 \%$ of patients in previous retrospective series. ${ }^{11-14}$ The risk of recurrence following adequate surgical resection depends on histological features (mitotic index), tumor size, and location. ${ }^{15,16}$ GISTs recur in the abdominal cavity or as liver metastases, rarely in the lung or bones.

Before imatinib, the prognosis for patients with recurrent or metastatic GIST was very poor, with a median overall survival (OS) of 9 to 18 months in most series. The development of imatinib mesylate has revolutionized the management of patients with locally advanced and metastatic GIST, leading to important gains in quality of life and survival. Several multi-institutional studies, with a total of more than 1800 enrolled patients, have now evaluated the efficacy of imatinib treatment of advanced/metastatic GIST. Imatinib was proven to significantly improve progression-free survival (PFS) and OS, with a median PFS of approximately 2 years and a median OS of nearly 5 years. ${ }^{17}$ Indeed these results come from the early studies, which were carried out early on the use of imatinib for GIST in the medical community and had an obvious unfavorable case mix, with several patients carrying high tumor volumes. In fact, treatment with imatinib achieves disease control in the majority of patients with metastatic GIST (80\% to 90\%) regardless of tumor size, ${ }^{17-21}$ but tumor size does have an adverse effect on time to progression. ${ }^{22}$ Imatinib approval for the systemic treatment of advanced/metastatic GIST in 2002 was a major advance in the therapeutic management of these patients. All current guidelines, including those of the European Society of Medical Oncology and the National Comprehensive Cancer Network, recommend imatinib as the standard of care in the first-line management of unresectable or metastatic GIST. ${ }^{10,23}$ A combined analysis of the two international EORTC and SWOG phase III trials (MetaGIST) showed that patients with mutations in exon 9 of KIT have a significantly longer PFS with high-dose $(800 \mathrm{mg})$ imatinib therapy compared to standard dose $(400 \mathrm{mg}) .^{21}$

\section{Pharmacology, pharmacokinetics and drug-drug interaction}

Imatinib mesylate (formerly referred to as STI 571, now Glivec ${ }^{\circledR}$ [Europe], Gleevec ${ }^{\circledR}$ [US]; Novartis) is a 2-phenilpyrimidine derivative, a small, orally bioavailable molecule that competitively binds to the adenosine triphosphate-binding pocket of certain tyrosine kinases, including c-kit, c-ABL, bcr-ABL, and PDGFR $\alpha$, thereby inhibiting kinase activity and causing interruption of the downstream signaling process that leads to cell proliferation. ${ }^{5,24,25}$

The pharmacokinetic profile of imatinib in patients with GIST is comparable to that seen in healthy volunteers, and in patients with chronic myelogenous leukemia (CML). ${ }^{7}$ Imatinib has a good oral absorption and a bioavailability of about $98 \%$, regardless of the preparation (solution, capsule, or tablet) or dosage strength (100 mg, $400 \mathrm{mg}) \cdot{ }^{26}$ Food does not affect imatinib absorption. ${ }^{27}$ Once absorbed, it highly binds to serum proteins (mainly albumin and alpha 1-acid glycoprotein). Peak plasma levels of imatinib occur in about 4 hours, and levels reach steady state within a week. ${ }^{7}$ The main circulating metabolite is an $\mathrm{N}$-demethylated piperazine derivative which accounts for $16 \%$ of the AUC (area under curve) for imatinib. This accounts for most of the imatinib activity, but there are a number of smaller metabolites. Most of the drug is metabolized by the cytochrome P450 isoenzyme 3A4 (CYP3A4), so co-administered drugs that induce or inhibit this enzyme may increase or decrease clearance of imatinib, respectively. Concomitant administration of CYP3A4 inhibitors (eg, ketoconazole) may increase and CYP3A4 inducers (eg, Hypericum [St. John's wort], rifampicin) may decrease imatinib systemic exposure $\left(\mathrm{C}_{\max }\right.$ and $\left.\mathrm{AUC}\right) .{ }^{28}$ Conversely, imatinib is a moderate inhibitor of CYP3A4 and may increase exposure to drugs metabolized by this isoenzyme, such as some statins. ${ }^{28,29}$ Furthermore imatinib has been shown to be potent competitive inhibitor of CYP2C9, CYP2D6 and CYP3A5; concomitant imatinib administration may result in elevated blood concentrations of drugs that are substrates of these enzymes. ${ }^{27}$ Imatinib may increase systemic exposure to paracetamol by inhibiting its O-glucorunidation. ${ }^{27}$ The terminal elimination half-life is approximately 18 hours, which allows for once a day dosage. Excretion is via the feces and urine, the majority being the metabolites. Age, race, sex, and bodyweight do not significantly affect the pharmacokinetics of the drug. ${ }^{26}$ 


\section{Safety and tolerability and management of adverse events}

Phases II and III clinical trials on advanced/metastatic GISTs demonstrated that imatinib was generally well tolerated at doses up to $800 \mathrm{mg}$ daily. Similar to the findings in CML trial patients, most adverse events in patients receiving imatinib for GIST were minor and manageable without the need for dose adjustment. Almost all patients $(\approx 99 \%)$ experienced adverse events; however, most of the events were of mild ${ }^{19}$ or mild to moderate ${ }^{20}$ severity. The most commonly reported side effects included edema (usually periorbital), anemia, diarrhea, nausea/vomiting, abdominal pain, muscle aches, fatigue, and rash. ${ }^{18,20}$ The incidence of serious adverse events was similar for the imatinib 400 and $800 \mathrm{mg} /$ day groups (37\% and $38 \%$ of patients) in the EORTC phase III trial. ${ }^{19}$ The side effect profile of imatinib may improve with prolonged therapy..$^{19}$ In an analysis of the tolerability profile before versus after crossover from the 400 to the $800 \mathrm{mg}$ /day arm (in the EORTC phase III trial), the incidences of anemia and fatigue were significantly increased, with $12.8 \%(P=0.015$ versus before crossover) and $7.5 \%(P=0.00001)$ of patients experiencing new grade $3 / 4$ events. ${ }^{30}$ On the other hand, no increase in grade 3-4 neutropenia was documented after crossover to the higher dosage $(P=0.002) .{ }^{30}$ Imatinib was generally well tolerated following long-term administration in GIST patients, according to tolerability data obtained from the US phase II study in which patients were followed up for a median of 41 months while receiving imatinib. ${ }^{17}$

\section{Efficacy}

Given the high risk of relapse following surgery for localized GISTs, especially for larger GISTs, and the efficacy of imatinib mesilate in the advanced setting, as well as its favorable safety profile, investigators hypothesized that imatinib mesilate given postoperatively after gross complete resection of primary GIST could delay or prevent recurrence and therefore improve survival. Furthermore, as the development of imatinib resistance appears to be due to the emergence or expansion of individual clones, the risk of developing such resistant clones might be reduced by using imatinib at an earlier stage. Thus a number of clinical trials have been investigating the merits of using adjuvant imatinib therapy.

The ACOSOG Z9000 phase II study addresses treatment with imatinib (400 mg/day orally) for 1 year, in patients with high-risk GIST (tumor size $>10 \mathrm{~cm}$, rupture, or $<5$ peritoneal metastases) who had undergone complete resection with no control arm. The results of this trial indicate that imatinib is associated with improved OS in comparison with historical controls. However, these controls refer to the era when imatinib was not available even for patients with advanced disease. The study enrolled 107 evaluable patients, with a median tumor size of $13 \mathrm{~cm}(3-42 \mathrm{~cm})$. Eighty-seven patients $(82 \%)$ completed the full year of imatinib therapy. Seventy-two patients $(68 \%)$ tolerated full dose imatinib without dose modification, 8 had a temporary dose reduction, and 7 finished at a lower dose. ${ }^{31,32}$ This phase II study confirmed the favorable safety profile of imatinib therapy in this setting. The 1-, 2-, and 3-year relapse-free survival (RFS) rates were $94 \%, 73 \%$, and $61 \%$, respectively. ${ }^{32}$ Nilsson and colleagues $^{33}$ reported their own experience with adjuvant imatinib of a single-center, in a consecutive pilot series of 23 patients with high-risk GIST who have been treated with adjuvant imatinib (400 mg/daily for 1 year) after R0 resection. These cases were compared with historical controls from previous population-based series treated with surgery alone. This study shows that 1 -year treatment of imatinib after R0 resection for high-risk GIST dramatically reduces the risk of recurrent disease. The results of this study and of the ACOSOG Z9000 study await confirmation from prospective adjuvant treatment trials.

Three randomized trials have been initiated to investigate the role of a $400 \mathrm{mg}$ daily dose of imatinib, given for 1 year versus placebo (ACOSOG Z9001) with RFS as the primary end-point, for 2 years versus observation alone (Intergroup GEIS/EORTC/ISG/FSG/AGITG 62024) with OS as the primary end-point or for 3 years versus 1 year in the SSG $\mathrm{XVIII/AIO} \mathrm{trial} \mathrm{with} \mathrm{RFS} \mathrm{as} \mathrm{the} \mathrm{primary} \mathrm{end-point.}$

Until the reporting of the ACOSOG Z9001 study consensus, clinical practice guidelines recommend including patients with resected non-metastatic disease in clinical trials of adjuvant therapy. ${ }^{10,34,35}$

The ACOSOG Z9001 trial was presented at ASCO meeting 2007, and preliminary data demonstrated a significant improvement in RFS, but not of OS, in patients with tumors $\geq 3 \mathrm{~cm}$ in diameter (hazard ratio in favor of imatinib 0.35 (95\% confidence interval $0.22-0.53) .{ }^{36}$ The study enrolled 713 patients with localized GIST having a diameter greater than $3 \mathrm{~cm} .{ }^{36}$ At the median follow-up of 19.7 months, $8 \%$ of patients in the imatinib group and $20 \%$ in the placebo group had recurrence or died. Imatinib significantly improved RFS compared with placebo ( $98 \%$ versus $83 \%$ at 1 year). In the updated report ${ }^{37}$ the difference in RFS was significant for all size subgroups (ie, $3-6 \mathrm{~cm}, 6-10 \mathrm{~cm}$, and $\geq 10 \mathrm{~cm}$ ). Adjuvant imatinib was well tolerated. Grade 1 and 2 events were common, and mostly involved GI effects (mild diarrhea, nausea and flatulence), headache, rash, periorbital or peripheral 
edema, fatigue, or myalgias or arhralgias. Two hundred and fifty-one patients (73\%) in the placebo group and $229(68 \%)$ in the imatinib group had a grade 1 or 2 event. Grade 3 or 4 events occurred in $63(18 \%)$ patients in the placebo group and $104(31 \%)$ in the imatinib group, the most common serious adverse events being dermatitis, abdominal pain and diarrhea in the imatinib group, and hyperglycemia in the placebo group. ${ }^{37}$ Adjuvant imatinib therapy is safe and improves RFS compared with placebo after the resection of primary GIST. No significant effect on OS was observed, because of the limited follow-up time, the limited number of relapses, the crossover design of the study which allowed patients assigned to the placebo group to receive imatinib on recurrence, and the considerably improved survival of patients in metastatic phase with imatinib. ${ }^{37}$ These updated results of this trial led to the Food and Drug Administration marketing approval (December 2008) of imatinib for the treatment of GIST in the adjuvant setting without definite guidance as to optimal duration of treatment or which patients should be most likely to benefit. The European Medicines Agency (EMEA) approved the use of adjuvant imatinib in March 2009. EMEA approval is restricted to patients at significant risk of relapse, without reference to what criteria should be used to make determination. Because of the potential toxic effects and the financial cost of the treatment, the ability to measure risk of recurrence for individual patients is important. The other phase III studies have just been completed, and results have therefore not been reported. At this stage several questions remain unanswered.

\section{Delay or prevention?}

The major question of whether adjuvant therapy will prevent relapse or only delay it remains unclear. In view of the observations gathered in advanced disease from the French BFR14 trial in particular, imatinib interruption at either 1 or 3 years is followed consistently by relapse at a median of 6 months. ${ }^{38,39}$ Although these are the only data available so far, a complete analogy with the adjuvant setting should be taken with caution. Yet it is possible that relapse may only be delayed, and not prevented, in the adjuvant setting, and the current survival curves in the ACOSOG Z9001 cannot exclude this possibility.

\section{Overall survival}

The aim of any adjuvant treatment is both to reduce the risk of relapse and, in particular, to increase OS. Therefore, today's ACOZOG Z9001 study is a self-fulfilling prophecy only. Patients with a high-risk of metastatic spread were given treatment with a highly effective drug which, unsurprisingly, yielded an improved RFS compared with placebo while receiving treatment. Whether this advantage translates into improved survival has yet to be shown. In the ACOSOG Z9001 study, OS did not differ between groups. Given the relatively limited risk of death from GIST in the first years following the initiation of imatinib for advanced disease, it is likely that the effect of adjuvant treatment on OS, if any, will not be apparent until 7 or 8 years following the completion of the EORTC 62024 trial.

\section{Patient selection}

The question of which patient population will benefit most from adjuvant imatinib is an important one. Accurate risk stratification is crucial for the selection of patients who are most likely to benefit from adjuvant imatinib therapy, initially in clinical trials and ultimately in clinical practice. It is known that multiple factors affect patient risk, including mitotic index, tumor size, site, mutation type, completeness of surgery, and rupture, ${ }^{16,40-43}$ but risk stratification with an optimal staging system has not been established and validated..$^{3,15,41,44-46}$ Two commonly used staging systems for prognosis were developed at a 2001 US National Institutes of Health (NIH) workshop (Table 1). ${ }^{15,44}$ A modification of one of these staging systems was then suggested in 2006 (Table 1). ${ }^{40}$ None of these staging systems provides a quantifiable risk of recurrence for individual patients. Gold and colleagues ${ }^{47}$ recently developed and validated a nomogram to predict RFS after resection of localized primary GIST. The nomogram, which takes into account tumor size (cm), location (stomach, small intestine, colon/rectum, or other), and mitotic index ( $<5$ or $\geq 5$ mitoses per 50 highpower fields) has better predictive accuracy, as determined by concordance probabilities, than two commonly used staging systems developed at the US NIH GIST workshop in 2001. It has a similar probability of concordance with the third staging system, Miettinen's Armed Forces Institute of Pathology (AFIP) system. ${ }^{40}$ Nomogram predictions of RFS seems better calibrated than predictions made with the Miettinen AFIP system. The inclusion of tyrosine kinase mutation status in the nomogram do not improve its discriminatory ability. The nomogram might be useful for patient care, interpretation of clinical trial results, and selection of patients for adjuvant imatinib therapy.

In 2008 , Joensuu ${ }^{42}$ proposed modifying the NIH consensus classification (based on tumor size and mitotic count) by introducing two important risk stratification factors in the $\mathrm{NIH}$ classification: site of origin and rupture. The modification of 
Table I Commonly used rating systems for assessing risk of GIST

\begin{tabular}{|c|c|}
\hline & Features \\
\hline \multicolumn{2}{|l|}{ NIH: Fletcher ${ }^{15}$} \\
\hline Very low & $<2 \mathrm{~cm}$ and $<5$ mitotic index \\
\hline Low & $2-5 \mathrm{~cm}$ and $<5$ mitotic index \\
\hline \multirow[t]{2}{*}{ Intermediate } & $5-10 \mathrm{~cm}$ and $<5$ mitotic index \\
\hline & $5 \mathrm{~cm}$ and $6-10$ mitotic index \\
\hline \multirow[t]{3}{*}{ High } & $>5 \mathrm{~cm}$ and $>5$ mitotic index \\
\hline & $>10 \mathrm{~cm}$ and any mitotic index or \\
\hline & any size and $>10$ mitotic index \\
\hline \multicolumn{2}{|l|}{ NIH: Miettinen ${ }^{44}$} \\
\hline \multirow[t]{2}{*}{ Probably benign } & Gastric: $\leq 5 \mathrm{~cm}$ and $\leq 5$ mitotic index \\
\hline & Intestinal: $\leq 2 \mathrm{~cm}$ and $\leq 5$ mitotic index \\
\hline Uncertain or low & $\begin{array}{l}\text { Gastric: }>5 \mathrm{~cm}, \leq 10 \mathrm{~cm} \text {, and } \leq 5 \text { mitotic } \\
\text { index }\end{array}$ \\
\hline Malignant potential & $\begin{array}{l}\text { Intestinal: }>2 \mathrm{~cm}, \leq 5 \mathrm{~cm} \text {, and } \leq 5 \text { mitotic } \\
\text { index }\end{array}$ \\
\hline \multirow[t]{2}{*}{ Probably malignant } & Gastric: $>10 \mathrm{~cm}$ or $>5$ mitotic index \\
\hline & Intestinal: $>5 \mathrm{~cm}$ or 5 mitotic index \\
\hline \multicolumn{2}{|l|}{ AFIP: Miettinen ${ }^{40}$} \\
\hline $\begin{array}{l}\text { Very low, if any malignant } \\
\text { potential }\end{array}$ & $\leq 2 \mathrm{~cm}$, and $\leq 5$ mitotic index \\
\hline \multirow[t]{2}{*}{ Low malignant potential } & $\begin{array}{l}\text { Gastric: }>2 \mathrm{~cm} \text { and } \leq 10 \mathrm{~cm} \text {, and } \leq 5 \\
\text { mitotic index; } \leq 2 \mathrm{~cm} \text {, and }>5 \text { mitotic } \\
\text { index }\end{array}$ \\
\hline & $\begin{array}{l}\text { Intestinal: }>2 \mathrm{~cm} \text { and } \leq 5 \mathrm{~cm} \text {, and } \leq 5 \\
\text { mitotic index }\end{array}$ \\
\hline Intermediate & Gastric: $>10 \mathrm{~cm}$ and $\leq 5$ mitotic index \\
\hline \multirow[t]{2}{*}{ Malignant potential } & $>2 \mathrm{~cm}$ and $\leq 5 \mathrm{~cm}$, and $>5$ mitotic index \\
\hline & $\begin{array}{l}\text { Intestinal: }>5 \mathrm{~cm} \text { and }<10 \mathrm{~cm} \text {, and } \leq 5 \\
\text { mitotic index }\end{array}$ \\
\hline High malignant & Gastric: $>5 \mathrm{~cm}$ and $>5$ mitotic index \\
\hline potential & Intestinal: $>10 \mathrm{~cm}$ or $>5$ mitotic index \\
\hline
\end{tabular}

Notes: mitotic index $=$ number of mitoses per 50 high-power field. Abbreviations: AFIP, Armed Forces Institute of Pathology; NIH, National Institutes of Health.

the NIH classification could be useful in selecting adult patients for clinical trials of adjuvant systemic treatment, and subsequently, if validated, for identifying which patients are most likely to benefit from adjuvant therapy. ${ }^{42}$

Standard of care for localized primary GIST after surgical resection has changed recently on the basis of the results of the ACOSOG Z9001 trial. The ACOSOG Z9001 trial was powered on RFS on the entire study population, which consisted of patients with tumors of $3 \mathrm{~cm}$ or more. Nevertheless, ad hoc analysis of size (which was the only stratification factor) showed significant differences in RFS between imatinib and placebo groups in each size category (ie, $3-6 \mathrm{~cm}, 6-10 \mathrm{~cm}$, and $\geq 10 \mathrm{~cm}$ ). ${ }^{37}$ Retrospective analysis of mitotic index assessed by central pathology review and location is underway. ${ }^{47}$ Once additional follow-up data and more events are obtained, further validation of the nomogram using the patients assigned to the placebo group should be done in the ACOSOG Z9001 study. Patients at low risk of recurrence might not need adjuvant imatinib. However, patients at high risk of relapse need postoperative therapy for periods longer than 1 year

\section{Duration of treatment}

The optimal duration of adjuvant imatinib is not known, and the only available data show the efficacy of 1-year treatment on RFS. Further clinical trials, which have already fully accrued, should address this issue satisfactorily. Two phase III trials aim to answer some of the outstanding questions on imatinib adjuvant therapy, the EORTC 62024 and SSG XVIII trials. The EORTC 62024 clinical trial is a controlled randomized trial comparing adjuvant imatinib (400 mg daily) for 2 years versus no further therapy after complete surgery for intermediate- and high-risk patients with localized, completely resected GIST expressing KIT. In this study the risk stratification is based on both size and mitotic index. Target accrual of 900 patients has been reached. The primary end-point is OS, with RFS, relapsefree interval, and safety as secondary end-points. Following the early interruption of the ACOSOG Z9001 trial, another secondary end-point was added: time to imatinib failure. Logically, this end-point provides a good surrogate for definitive efficacy of adjuvant therapy. This trial will also provide important information on the question of the optimal treatment duration.

The SSG XVIII study is an open-label, randomized, prospective, phase III trial, and includes patients with highrisk GIST treated with imatinib (400 $\mathrm{mg}$ daily) for either 1 or 3 years. The accrual target of 400 patients has been met. The primary objective is to investigate the RFS within the first 5 years following diagnosis. Secondary objectives are the investigation of feasibility of adjuvant imatinib therapy, OS, and GIST-specific survival. Although the results of the SSG XVIII/AIO trial comparing 1 versus 3 years are not yet available, it is likely that RFS will be better for the 3-year arm, since there is no reason to believe that the outcome of patients may be different in the minimal residual disease setting. However, only the SSG XVIII/AIO trial will provide a conclusive, reliable answer to the question of optimal duration of adjuvant therapy. 


\section{Dose}

KIT exon 9 mutated tumors benefit from a $800 \mathrm{mg} /$ day dose in an advanced phase, but the effect of such dose in the adjuvant setting has not yet been explored. ${ }^{21,48}$ Similarly, some (but not all) exon 18 PDGFRA mutations such as D842V, which are seen in gastric GISTs, appear to be relatively indolent but are less likely to be as sensitive as GISTs with KIT mutations in the adjuvant setting, even though this needs to be formally explored, as data are available at this stage only in vitro and in a metastatic setting. ${ }^{49,50}$ The question of whether different molecular subtypes of GIST should receive different adjuvant treatment will need to be carefully addressed in the currently ongoing or completed studies.

\section{Conclusion}

From the studies conducted so far, it is clear that high-risk GIST patients need treatment, but we do not know to what extent imatinib will improve OS. It seems very likely that 1 year of imatinib is not enough for those who do need it. The SSG XVIII and EORTC studies will help to answer the question of the optimal duration treatment and survival. When the question of risk assessment by different criteria ${ }^{15,40,42}$ arises, the decision should always be made on the most stringent assessment. Today, physicians and patients are therefore put in a difficult situation of not having all the answers (ultimate benefit in terms of OS, optimal duration of treatment, prevent or delay of relapse, and so on) with which to make a meaningful and scientifically based decision.

\section{Disclosure}

The authors declare no conflicts of interest.

\section{References}

1. Van der Zwan SM, De Matteo RP. Gastrointestinal stromal tumor: 5 years later. Cancer. 2005;103:1781-1788.

2. Mucciarini C, Rossi G, Bertolini F, et al. Incidence and clinicopathologic features of gastrointestinal stromal tumors. A population-based study. BMC Cancer. 2007; 7:230.

3. Nilsson B, Bumming P, Meis-Kindblom JM, et al. Gstrointestinal stromal tumors: the incidence, prevalence, clinical course, and prognostication in the preimatinibmesylate era- a population based study in western Sweden. Cancer. 2005;103:821-829.

4. Steigen SE, Eide RJ. Trends in incidence and surzvival ofmesenchymal neoplasm of the digestive tract within a defined population of northern Norway. APMIS. 2006;114:192-200.

5. Pidhorecky I, Cheney RT, Kraybill WG, Gibbs JF. Gastrointestinal stromal tumors: current diagnosis, biologic behaviour, and management. Ann Surg Oncol. 2000;7:705-712.

6. Corless CL, Heinrich MC. Molecular pathobiology of gastrointestinal stromal sarcomas. Annu Rev Pathol. 2008;3:557-586.

7. D'Amato G, Steinert DM, McAuliffe JC, Trent JC. Update on thebiology and therapy of gastrointestinal stromal tumors. Cancer Control. 2005;12:44-56.
8. Chompret A, Kannengiesser C, Barrois M, et al. PDGFRA germline mutation in a family with multiple cases of gastrointestinal stromal tumor. Gastroenterology. 2004;126:318-321.

9. Nishida T, Hirota S, Taniguchi M, et al. Familial gastrointestinal stromal tumours with germline mutation of the KIT gene. Nat Genet. 1998;19:323-324.

10. Demetri GD, Benjamin RS, Blnacke CD, et al. NCCN Task Force. NCCN Task Force report: management of patients with gastrointestinal stromal tumor (GIST)-update of the NCCN clinical practice guidelines. J Natl Compr Cancer Netw. 2007;5(Suppl 2):S1-S29.

11. DeMatteo RP, lewis JJ, Leung D, et al. Two hundred gastrointestinal stromal tumors: recurrence patterns and prognostic factors for survival. Ann Surg. 2000;213:51-58.

12. DeMatteo RP, Gold JS, Saran L, et al. Tumor mitotic rate, size, and location independently predict recurrence after resection of primary gastrointestinal stromal tumor (GIST). Cancer. 2008;112:608-615.

13. Plaat BE, Hollema H, Molenaar WM, et al. Soft tissue leiomyosarcomas and malignant gastrointestinal stromal tumors: differences in the clinical outcome and expression of multidrug resistance proteins. J Clin Oncol. 2000;18:3211-3220.

14. Hsu KH, Yang TM, Shan YS, Lin PW. Tumor size is a major determinant of recurrence in patients with resectable gastrointestinal stromal tumor. Am J Surg. 2007;194:148-152.

15. Fletcher CD, Berman JJ, Corless C, et al. Diagnosis of gastrointestinal stromal tumors: a consensus approach. Hum Pathol. 2002;33:459-465.

16. Miettinen M, Sobin LH, Lasota J. Gastrointestinal stromal tumors of the stomach: a clinicopathologic, immunohistochemical, and molecular genetic study of 1765 cases with long-term follow-up. Am J Surg Pathol. 2005;29:52-68.

17. Blanke CD, Demetri GD, von Mehren M, et al. Long-term results from a randomized phase II trial of standard versus versus higher-dose imatinib mesylate for patients with unresectable gastrointestinal stromal tumors expressing KIT. J Clin Oncol. 2008;26:620-625.

18. Verweij J, van Oosterom A, Blay JY, et al. Imatinib mesylate (STI 571 Glivec $^{\mathbb{R}}$, Gleevec) is an active agent for gastrointestinal stromal tumours, but does not yield responses in other soft-tissue sarcomas that are unselected for a molecular target. Results from an EORTC Soft Tissue and Bone Sarcoma Group phase II study. Eur J Cancer. 2003;39:2006-2011.

19. Verweij J, Casali PG, Zalcberg J, et al. progression-free survival in gastrointestinal stromal tumours with high-dose imatinib: randomised trial. Lancet. 2004;364:1127-1134.

20. Demetri GD, ven Mehren M, Blanke CD, et al. Efficacy and safety of imatinib mesylate in advanced gastrointestinal stromal tumors. $N$ Engl J Med. 2002;347:472-480.

21. Van Glabbeke MM, Owzar K, Rnakin C, et al. Comparison of two doses of imatinib for the treatment of unresectable or metastatic gastrointestinal stromal tumors (GIST): a meta analysis base don 1,640 patients (pts). J Clin Oncol. (Meeting Abstracts) 2007;25(18 Suppl):10004.

22. Van Glabekke M, Verweij J, Casali PG, et al. Initial and late resistance to imatinib in advanced gastrointestinal stromal tumors are predicted by different prognostic factors : a European organisation for research and treatment of cancer-italian sarcoma group-australasian gastrointestinal trials group study. J Clin Oncol. 2005;23:5795-5804.

23. Casali PG, Jost L, Reichardt P, Schlemmer M, Blay JY, et al; for the ESMO Guidelines working Group. Gastrointestinal stromal tumors: ESMO clinical recommendations for diagnosis, treatment, and follow up. Ann Oncol. 2009;20 Suppl 4:64-67.

24. Judson I. Gastrointestinal stromal tumour (GIST): biology and treatment. Ann Oncol. 2002;13(Suppl 4):287-289.

25. Gold JS, DeMatteo RP. Combined surgical and molecular therapy: the gastrointestinal stromal tumor model. Ann Surg. 2006;244:176-184.

26. Peng B, Llyod P, Schran H. Clinical pharmacokinetics of imatinib. Clin Pharmacokinet. 2005;44:879-894.

27. Novartis Europharm Limited. Product information (EU): Glivec ${ }^{\circledR}$ (imatinib mesylate) tablets $100 \mathrm{mg}$ and $400 \mathrm{mg}$. http://www.emea. eu.int/. Accessed Jan 22, 2007. 
28. Asif M, Siddiqui A, Scott LJ. Imatinib. A Review of its use in the management of gastrointestinal stromal tumors. Drugs. 2007;67: 805-820.

29. Demetri GD, Benjamin RS, Blanke CD, et al. NCCN Task Force report: optimal management of patients with gastrointestinal stromal tumor (GIST)-expansion and update of NCCN Clinical Practice Guidelines. J Natl Compr Canc Netw. 2004;2(Suppl 1):S1-S26.

30. Zalcberg JR, Verweij J, Casali PG, et al. Outcome of patients with advanced gastro-intestinal stromal tumours crossing-over to a daily imatinib dose of $800 \mathrm{mg}$ after progression of $400 \mathrm{mg}$. Eur J Cancer. 2005;41:1751-1757.

31. DeMatteo RP, Antonescu CR, Chadaram V, et al. Adjuvant imatinib mesylate in patients with primary high risk gastrointestinal stromal tumor (GIST). 38th Annual Meeting of the ASCO. Orlando, FL 2002 J Clin Oncol. 2002(Suppl):Abstract 1610.

32. DeMatteo RP, et al. 2008 GastroIntestinal Cancers Symposium Abstract 8 (2008)

33. Nilsson B, Sjolund K, Kindblom LG, Meis-Kindblom JM, Bumming P, Nilsson O. Adjuvant imatinib treatment improves recurrence-free survival in patients with high-risk gastrointestinal stromal tumours (GIST). Br J Cancer. 2007;96:1656-1658.

34. Blay JY, Bonvalot S, Casali PG, et al. GIST consensus meeting panellist. Consensus meeting for the management of gastrointestinal stromal tumors. Report of the GIST Consensus Conference of 20-21 March 2004, under the auspices of ESMO. Ann Oncol. 2005;16:566-578.

35. Casali PG, Jost L, Reichardt P, Schlemmer M, Blay JY; on behalf of the ESMO Guidelines Working Group. Gastrointestinal stromal tumors.: ESMO clinical recommendations for diagnosis, treatment, and follow-up. Ann Oncol. 2008;19(Suppl II):35-38.

36. DeMatteo RP, Owzar K, Maki R, et al. Adjuvant imatinib mesylate increases recurrence-free survival (RFS) in patients with completely resected localized primarygastrointestinale stromal tumor (GIST): North American Intergroup Phase III trial ACOSOG Z9001. J Clin Oncol. (Meeting Abstracts) 2007;25(18 Suppl):10079.

37. DeMatteo RP, Ballman KV, Antonescu CR, Maki RG, Pisters PW, Demetri GD, et al. Adjuvant imatinib mesylate after resection of localised, primary gastrointestinal stromal tumour: a randomised, double-blind, placebo-controlled trial. Lancet. 2009;373:1097-1104.

38. Blay JY, Le Cesne A, Ray-Coquard, Bui B, Duffaud F, et al. Prospective multicentric randomized phase III of imatinib in patients with advanced gastrointestinal stromal tumors comparing interruption versus continuation of treatment beyond one year: the French Sarcoma Group. J Clin Oncol. 2007;25:1107-1113.
39. Le Cesne A, Ray-Coquard I, Bui B, et al. Continuous versus interruption of imatinib (IM) in responding patients with advanced GIST after three years of treatment: A prospective randomized phase III trial of the French Sarcoma Group. J Clin Oncol. (Meeting Abstracts) 2007;25(18 Suppl):10005.

40. Miettinen M, Lasota J. Gastrointestinal stromal tumors: review on morphology, molecular pathology, prognosis, and differential diagnosis. Arch Pathol Lab Med. 2006;130:1466-1478.

41. Miettinen M, Lasota J. Gastrointestinal stromal tumors: pathology and prognosis at different sites. Semin Diagn Pathol. 2006;23:79-83.

42. Joensuu $H$. Risk stratification of patients diagnosed with gastrointestinal stromal tumor. Hum Pathol. 2008;39:1411-1419.

43. Martin J, Poveda A, Llombart-Bosch A, et al. Deletions affecting codons $557-558$ of the c-kit gene indicate a poor prognosis in patients with completely resected gastrointestinal stromal tumors. A study by the Spanish group for sarcoma research (GEIS). J Clin Oncol. 2005;23:6190-6198.

44. Miettinen M, El-Rifai W, HL Sobin L, Lasota J, et al. Evaluation of malignancy and prognosis of gastrointestinal stromal tumors: a review. Hum Pathol. 2002;33:478-483.

45. Huang HY, Li CF, Huang WW, et al. A modification of NIH consensus criteria to better distinguish the highly lethal subset of primary localized gastrointestinal stromal tumors: a subdivision of the original high-risk group on the basis of outcome. Surgery. 2007;141: $748-756$.

46. Goh BK, Chow PK, Yap WM, et al. Which is the optimal risk straficitation system for surgically treated localized primary GIST? Comparison of three contemporary prognostic criteria in 171 tumors, and proposal for a modified Armed Forces Institute of Pathology risk criteria. Ann Surg Oncol. 2008;15:2153-2163.

47. Gold J, Gonen M, Gutierez A, Broto XM, Gacia-del-Muto X, Smyrk T, et al. development and validation of a prognostic nomogram for recurrence-free survival after complete surgical resection of localised primary gastro-intestinal stromal tumour: a retrospective analysis. Lancet Oncol. 2009. 10 November. [Epub ahead of print].

48. Debiec-Richter M, Sciot R, Le Cesne A, et al. KIT mutations and dose selection for imatinib in patients with advanced gastrointestinal stromal tumours. Eur J Cancer. 2006;42:1093-1103.

49. Heinrich MC, Corless CL, Rankin C, et al. PDGFRA activating mutations in gastrointestinal stromal tumors. Science. 2003;299:708-710.

50. Corless CL, Schroeder A, Griffith D, et al. PDGFRA mutations in gastrointestinal stromal tumors: frequency, spectrum and in vivo sensitivity. J Clin Oncol. 2005;23:2357-2364.
Clinical and Experimental Gastroenterology

\section{Publish your work in this journal}

Clinical and Experimental Gastroenterology is an international, peerreviewed, open access journal, publishing all aspects of gastroenterology in the clinic and laboratory, including: Pathology, pathophysiology of gastrointestinal disease; Investigation and treatment of gastointestinal disease; Pharmacology of drugs used in the alimentary tract;

\section{Dovepress}

Immunology/genetics/genomics related to gastrointestinal disease. This journal is indexed on CAS. The manuscript management system is completely online and includes a very quick and fair peer-review system. Visit http://www.dovepress.com/testimonials.php to read real quotes from published authors. 